\title{
QUEEN'S
UNIVERSITY
BELFAST
}

\section{An introduction to zwitterionic salts}

Blesic, M., Gilmore, B. F., Holbrey, J. D., Jacquemin, J., Level, G., Nockemann, P., \& Stella, L. (2017). An

introduction to zwitterionic salts. Green Chemistry, 19(17), 4007-4011. https://doi.org/10.1039/c7gc01523b

\author{
Published in: \\ Green Chemistry
}

Document Version:

Peer reviewed version

Queen's University Belfast - Research Portal:

Link to publication record in Queen's University Belfast Research Portal

Publisher rights

(C) 2017 The Royal Society of Chemistry.

This work is made available online in accordance with the publisher's policies. Please refer to any applicable terms of use of the publisher.

\section{General rights}

Copyright for the publications made accessible via the Queen's University Belfast Research Portal is retained by the author(s) and / or other copyright owners and it is a condition of accessing these publications that users recognise and abide by the legal requirements associated with these rights.

Take down policy

The Research Portal is Queen's institutional repository that provides access to Queen's research output. Every effort has been made to ensure that content in the Research Portal does not infringe any person's rights, or applicable UK laws. If you discover content in the Research Portal that you believe breaches copyright or violates any law, please contact openaccess@qub.ac.uk. 


\section{Introduction to Zwitterionic Salts}

Marijana Blesic ${ }^{a^{*}}$, Brendan F. Gilmore ${ }^{b}$, John D. Holbrey ${ }^{a}$, Johan Jacquemin ${ }^{a, c}$, Gaelle Level $^{a}$, Peter Nockemann ${ }^{a}$, Lorenzo Stella ${ }^{d}$

Zwitterionic salts are hybrid materials, incorporating some characteristics of zwitterions and of ionic liquids, e.g. numerous options for structural design and functionalisation. They comprise of cations and anions in which an additional zwitterionic moiety is embedded into either the cation or the anion. Such materials are characterised by having extended polar domains and high hydrophilicity. Here, we present results from the study of novel zwitterionic salts that are representative examples of this class of materials and illustrate the potential to exploit their functionality and high hydrophilicity.

There is significant interest is generating new highly hydrophilic additives or functional groups that can exceed the performance of doubly-charged zwitterions which are the established benchmark for applications where superhydrophilicity is required, e.g. for fouling-resistant surfaces. ${ }^{1-3}$ Short-chain zwitterionic salts (ZWSs) are new materials that contain multiple charge centres in the cationic or the anionic moiety, but only an overall +1 or -1 charge (Fig. 1). It is anticipated that this should lead to strong overall interactions with polar and associative solvents. This will enable novel hydrophilic additives to be prepared that incorporate some of the favourable characteristics of zwitterions and zwitterionic ionic liquids ${ }^{4,5}$ without producing highly charged polyelectrolytes or polyampholytes that are characterised by low solubility. At the same time, ZWSs could preserve advantages of some betaine zwitterions such as effective peptide immobilisation via EDS/NHS coupling. ${ }^{6}$

ZWSs (Fig. 1) consist of a cation and an anion, and an additional zwitterionic moiety embedded either in the cation or the anion. Okada and co-workers ${ }^{7,8}$ and later, Wang et al. ${ }^{9}$ have described the surface activity and phase behaviour of some zwitterion-containing sulfonate surfactants. However, the preparation and properties of smaller, non-surfactant salts have not previously been reported. At the moment, the lack of knowledge and experimental data on these materials hinders establishment of guidelines for their design and development of potential applications. Overcoming these limitations is the main goal of this work.
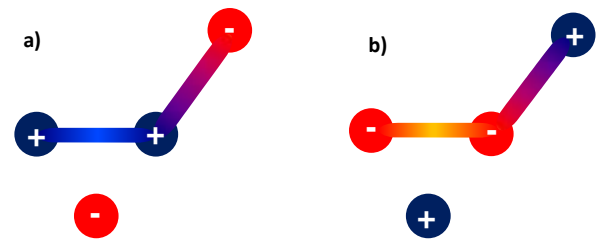

Fig. 1 Pictorial structure of zwitterionic salts with zwitterionic part embedded in a) cation and b) anion.

Herein, we describe a family of representative ZWSs which use ethylene diamine as a core structural motif for cations that include a zwitterionic moiety (Scheme 1). One terminal alkyl ammonium group incorporates ethyl, butyl, hexyl, hydroxyl, or methoxyethyl groups, while the second ammonium group is bound to either a carboxylate or sulfonate group forming a zwitterionic part of the molecule. A series of ZWSs were prepared to test these concepts using a simple two-step synthetic procedure as shown in Scheme 1, to first generate a single cationic site and then to introduce the zwitterionic function. The reactions were all performed with high yields, short reaction times, and under mild reaction conditions $\left(30-40{ }^{\circ} \mathrm{C}\right)$. This makes the materials readily available and simple to modify. Details of the synthesis and characterisation by CHNS analysis, mass spectroscopy, ${ }^{1} \mathrm{H}-$ and ${ }^{13} \mathrm{C}-\mathrm{NMR}$ spectroscopy can be found in the ESI. +

All the salts were isolated as solids. The melting points and decomposition temperatures are shown in Table 1. Decomposition temperatures calculated as onset of weight loss in a dynamic thermogravimetric analysis (TGA) scan show that the sulfonate based ZWSs have reasonable thermal stability with decomposition temperatures between 200-230 ${ }^{\circ} \mathrm{C}$. Similar decomposition temperature ranges have been reported for 1-alkyl-3-methylimidazolium carboxylate ionic liquids. ${ }^{10}$ Stability of carboxylate based ZWSs is, however, significantly lower.

Melting points are lower than those for common inorganic salts, but higher than $100{ }^{\circ} \mathrm{C}$. Applying the broad definition of ionic liquids as 'ionic salts which are molten at temperatures below $100{ }^{\circ} \mathrm{C}$ ', 11 these ZWSs cannot be classified as ionic liquids. However, there is a possibility that exchange of bromide anion with a larger, flexible, charge delocalised anion such as bis\{(trifluoromethyl)sulfonyl)\}imide would significantly lower the melting point, as already well-documented for ionic liquids. ${ }^{11}$ 


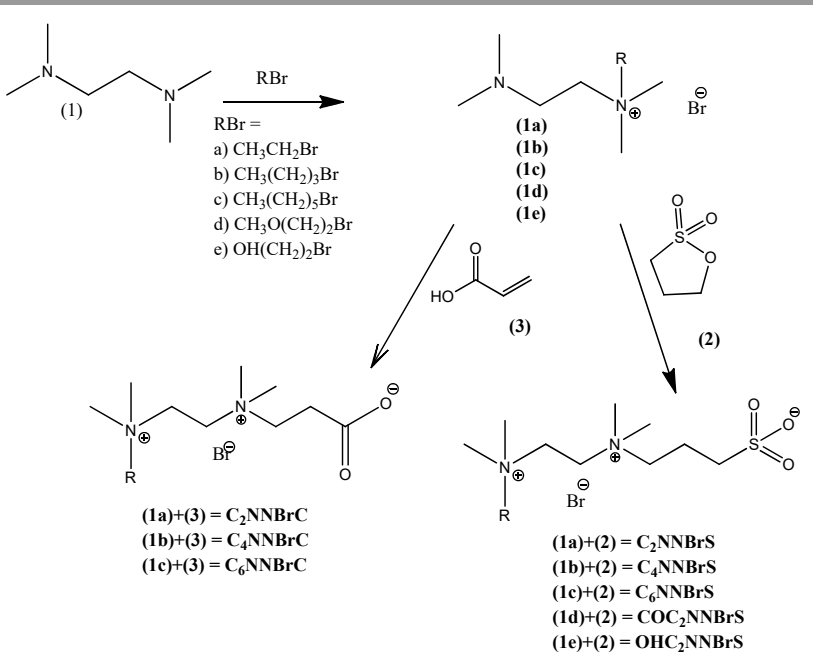

Scheme 1. The synthetic scheme

Table 1. Melting points $\left(T_{\mathrm{m}}\right)$ and decomposition temperature $\left(T_{\text {dec }}\right)$ of synthesised ZWSs.

\begin{tabular}{|c|c|c|}
\hline ZWS & $\boldsymbol{T}_{\mathrm{m}} /{ }^{\circ} \mathbf{C}$ & $\boldsymbol{T}_{\text {dec }} /{ }^{\circ} \mathbf{C}$ \\
\hline $\mathrm{C}_{2} \mathrm{NNBrS}$ & 124 & 242 \\
\hline $\mathrm{C}_{4} \mathrm{NNBrS}$ & 132 & 235 \\
\hline $\mathrm{C}_{6} \mathrm{NNBrS}$ & $-^{\mathrm{a}}$ & 224 \\
\hline $\mathrm{COC}_{2} \mathrm{NNBrS}$ & $-^{\mathrm{a}}$ & 210 \\
\hline $\mathrm{OHC}_{2} \mathrm{NNBrS}$ & 159 & 220 \\
\hline $\mathrm{C}_{2} \mathrm{NNBrC}$ & 115 & 140 \\
\hline $\mathrm{C}_{4} \mathrm{NNBrC}$ & 110 & $-^{\mathrm{b}}$ \\
\hline $\mathrm{C}_{6} \mathrm{NNBrC}$ & 130 & $-^{\mathrm{b}}$ \\
\hline
\end{tabular}

a-compound decomposed without melting, ${ }^{b}$-decomposition event was following the melting and the temperatures could not be clearly distinguished.

Crystals of $\mathrm{C}_{2} \mathrm{NNBrS}$ and $\mathrm{C}_{2} \mathrm{NNBrC}$ were obtained from solution and were characterised by single crystal diffraction. Details on the crystal preparation and crystallographic characterisation can be found in ESI. + Although crystals were isolated from methanol/acetone solutions, $\mathrm{C}_{2} \mathrm{NNBrS}$ crystallised with three water molecules in the asymmetric unit, indicating the high affinity towards water and adsorption ability. The crystal structure of $\mathrm{C}_{2} \mathrm{NNBrS} \cdot 3 \mathrm{H}_{2} \mathrm{O}$ (Fig. 2a) shows the sulfonate group forming hydrogen bonds with water molecules with an $\mathrm{O} \cdots \mathrm{H}$ distance of $1.872(2) \AA$; the water molecules also form additional hydrogen bonds with adjacent water molecules $(\mathrm{O} \cdots \mathrm{H}$ distance of $1.935(2) \AA \AA$ ). The bromide anions form only weak hydrogen bonding with one of the water molecules in the structure with a $\mathrm{Br} \cdots \mathrm{H}$ distance of 2.4432(2) $\AA$. The water molecules and bromide anions form layers separated by the cations are shown in Fig. S4 ESIt. Similar bridging of zwitterions by water molecules was recently reported by Fucke et al. ${ }^{12}$ This behaviour is not surprising, knowing that some quaternary ammonium salts also form crystalline hydrates with high proportion of 'crystal water'. ${ }^{13}$

It should be noticed that the water molecules can be removed from the structure $\mathrm{C}_{2} \mathrm{NNBrS}$ by drying the salt under high vacuum $(1 \mathrm{~Pa})$ and at a moderate temperature $\left(55^{\circ} \mathrm{C}\right)$ down to $300-500 \mathrm{ppm}$ as measured by coulometric Karl-Fischer titration. However, the removal of water from carboxylate ZWSs under identical condition is not efficient and usually leaves hydrates with 2000-5500 ppm of water.

$\mathrm{C}_{2} \mathrm{NNBrC}$, in contrast to $\mathrm{C}_{2} \mathrm{NNBrS}$, crystallised as a methanol solvate from a methanol/acetone solution, (Fig. 2b) containing a neutral (protonated) carboxylic acid function. There are two bromide anions and two methanol molecules present in the asymmetric unit. The carboxylic acid group of the cation forms weak hydrogen bonds with one of the bromide anions present in the structure with a $\mathrm{Br} \cdots \mathrm{H}$ distance of 2.3888(8) $\AA$. The second bromide anion in the structure forms a weak hydrogen bond with the methanol solvent molecule with an $\mathrm{O} \cdots \mathrm{H}$ distance of $2.4885(9) \AA ̊$. 
a)

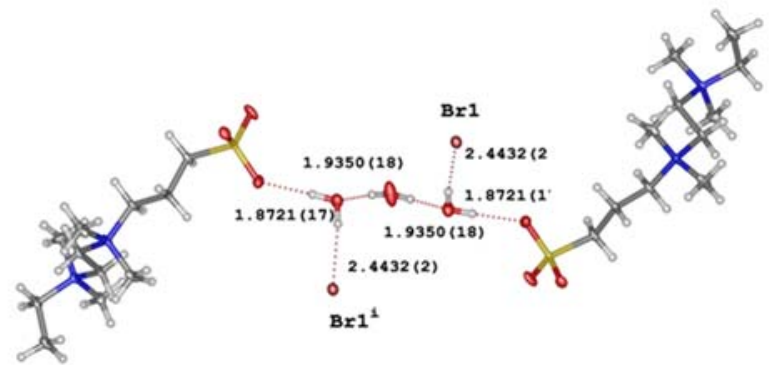

b)

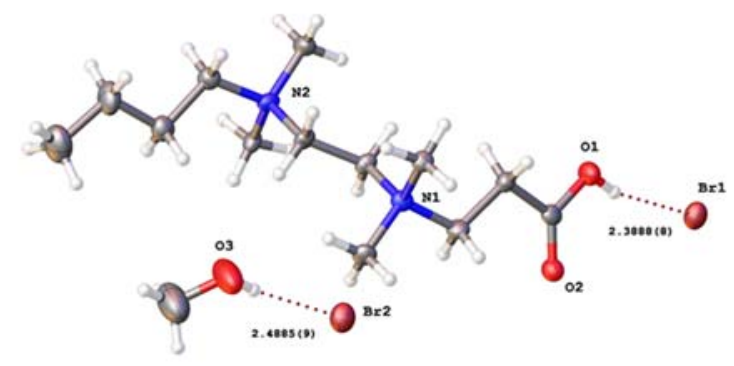

Fig. 2. a) Cation-cation association in crystal of $\mathrm{C}_{2} \mathrm{NNBrS}$ and b) $\mathrm{C}_{2} \mathrm{NNBrC}$ crystal with a methanol molecule in the structure.

Unlike most ionic liquids, which are usually soluble in many organic solvents such as acetone, acetonitrile, or chloroform, ZWSs have very limited solubility in these solvents. ZWSs exhibit high solubility in water at room temperature approaching $80 \mathrm{wt} \%$ (Table 2). For comparison, the solubilities of the simple tetraalkylammonium bromides, $\left[\mathrm{N}\left(\mathrm{CH}_{3}\right)_{4}\right] \mathrm{Br}$ and $\left[\mathrm{N}\left(\mathrm{C}_{2} \mathrm{H}_{5}\right)_{4}\right] \mathrm{Br}$ in water are 51 and $72 \mathrm{wt} \%$, respectively. ${ }^{13}$ Despite their low solubility in organic solvents, we have found that these salts associate via hydrogen bond interactions with a range of organic molecules that possess hydrogen bond donor ability forming homogenous mixtures which are liquid at room or close to room temperature. ${ }^{14}$ As an additional observation, aqueous ternary mixtures revealed an impressively rich phase behaviour. ${ }^{14}$

Table 2. Visually determined solubility of ZWSs in water at $25^{\circ} \mathrm{C}$.

\begin{tabular}{|c|c|c|c|c|}
\hline \multirow{2}{*}{$\begin{array}{c}\text { solubility, } \\
\text { wt\% }\end{array}$} & $\mathrm{C}_{2} \mathrm{NNBrS}$ & $\mathrm{C}_{6} \mathrm{NNBrS}^{a}$ & $\mathrm{OHC}_{2} \mathrm{NNBrS}^{a}$ & $\mathrm{C}_{2} \mathrm{NNBrC}$ \\
\cline { 2 - 5 } & 75 & 74 & 81 & 61 \\
\hline
\end{tabular}

a-Solubility test of $\mathrm{C}_{6} \mathrm{NNBrS}$ and $\mathrm{OHC}_{2} \mathrm{NNBrS}$ in acetone, acetonitrile, chloroform, toluene, 1,4 dioxane, ethyl acetate and dichloromethane show solubility below the limit of ${ }^{1} \mathrm{H}-\mathrm{NMR}$ detection.

Solutions of the ZWSs in water all show solid-liquid equilibria (SLE) points below $0{ }^{\circ} \mathrm{C}$, with a depression of the melting point temperatures as the concentration of ZWS is increased until the concentration of approx. $70 \mathrm{wt} \%$ ZWS. The SLE diagram for $\mathrm{C}_{2} \mathrm{NNBrS}$ and $\mathrm{C}_{6} \mathrm{NNBrS}$ are shown in ESI, Fig. S1+. At concentration higher than 70 wt\% of ZWSs, melting points and eutectic compositions could not be determined with accuracy due to the high viscosities of the solutions and steep slope of the temperature-concentration dependence.

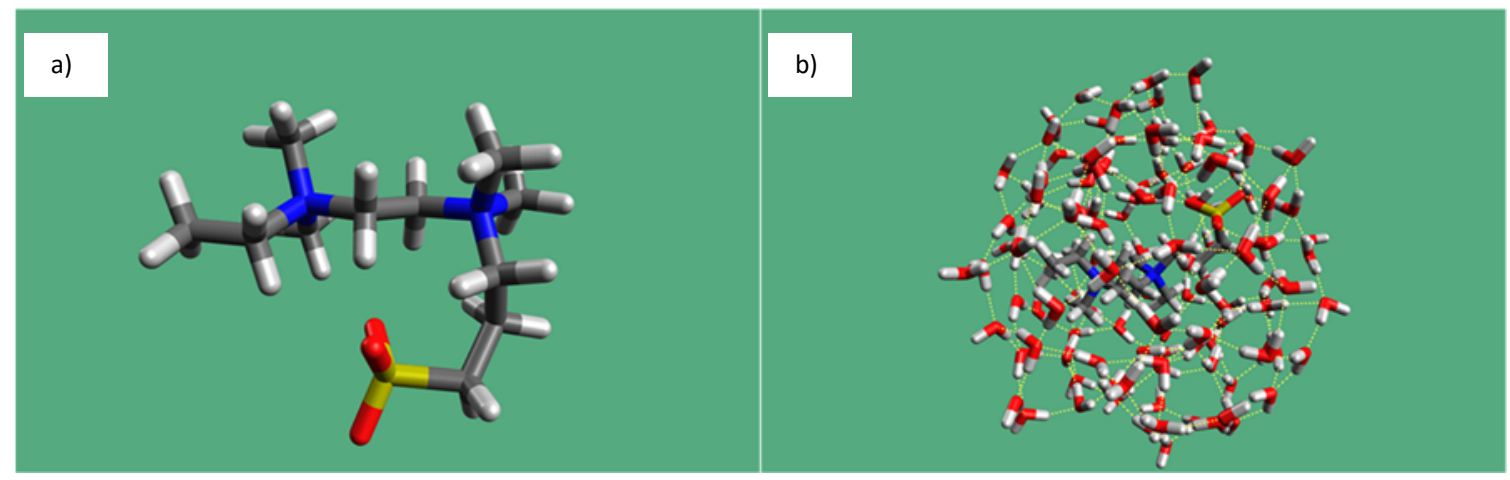

Fig. 3. a) Optimised gas phase geometry of $C_{2}$ NNS cation, b) 'Quenched' micro-solvation showing that the cation forms hydrogen bonds only with the water molecules.

In order to understand more about the solvation of ZWSs with water, the cation solvation structure was investigated using molecular modelling. The gas phase optimised geometries for isolated ZWS cations (reported in ESI + ) show a 
tendency to fold in order to minimise their electrostatic energy and form intramolecular hydrogen bonds. The extent of this depends on the molecular geometry. The main points of intramolecular interactions are negatively charged oxygen atoms in sulfonate and acidic protons on methylene groups located between positively charged tetraalkylammonium groups (see the optimised structure of the $\mathrm{C}_{2}$ NNS cation in Fig. 3a and b). However, when the cation geometry was refined using an implicit model of an aqueous solvent environment, a less compact structure was found. In addition, the intramolecular hydrogen bonds were completely disrupted (Figure S2 ESI †). Preliminary numerical result suggests preferential hydrogen-bonded solvation by water in solution supporting observations of high solubility and hydrophilicity.

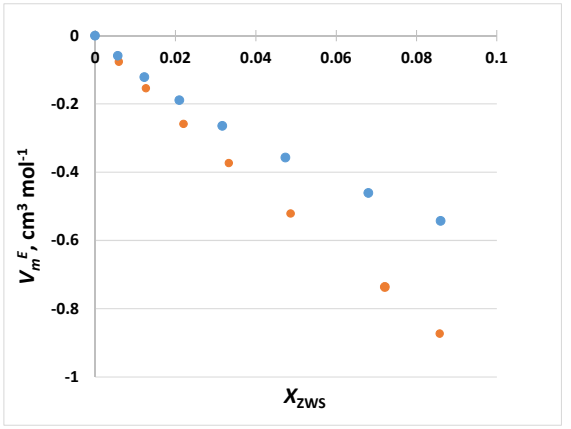

Fig 4. Excess molar volume, $V_{m}{ }^{E}$, as function of molar fraction of ZWS, $x_{z W S}$, for (ZWS+ water) binary system at $T=25^{\circ} \mathrm{C} ; \cdot \mathrm{C}_{2} \mathrm{NNBrS}$ and $\bullet \mathrm{OHC}_{2} \mathrm{NNBrS}$.

Table 3. Excess molar volumes, $V_{m}{ }^{E}$ measured at $T=25{ }^{\circ} \mathrm{C}$ and atmospheric pressure, for $\mathrm{C}_{2} \mathrm{NNBrS}, \mathrm{OHC}_{2} \mathrm{NNBrS}$, ethylammonium acetate, $\mathrm{N}_{2} \mathrm{Ac},{ }^{15} \mathrm{n}-$ butylammonium acetate, $\mathrm{N}_{4} \mathrm{Ac},{ }^{16}$ and n-butylammonium nitrate $\mathrm{N}_{4} \mathrm{NO}_{3}{ }^{16}$.

\begin{tabular}{|c|c|c|c|c|c|}
\hline Salt & $\mathrm{C}_{2} \mathrm{NNBrS}$ & $\mathrm{OHC}_{2} \mathrm{NNBrS}$ & $\mathrm{N}_{2} \mathrm{Ac}$ & $\mathrm{N}_{4} \mathrm{Ac}$ & $\mathrm{N}_{4} \mathrm{NO}_{3}$ \\
\hline $\boldsymbol{X}_{\text {salt }}$ & 0.086 & 0.086 & 0.09 & 0.0992 & 0.1000 \\
\hline $\boldsymbol{V}_{\boldsymbol{m}}{ }^{\boldsymbol{}}$ & -0.873 & -0.543 & -0.634 & -0.974 & -0.398 \\
\hline
\end{tabular}

The acidic protons associated with both alkyl ammonium cationic sites, the negatively charged oxygen atoms in sulphate or carboxylate anionic groups, and the bromide anions should all be available to contribute to strong interactions with water in solution via hydrogen bonding. In order to assess the strength of the interactions, excess molar volumes, $V_{m}{ }^{E}$, were calculated from experimental density data for two (ZWS + water) mixtures according to the following equation:

$$
V_{m}^{E}=\sum_{i} x_{i} M_{i}\left(\frac{1}{\rho}-\frac{1}{\rho_{i}}\right)
$$

where $\rho$ is the density of the solution, and $\rho_{i}$ and $M_{i}$ are the density and molecular weight of the pure component $i$, respectively. The density of $\mathrm{C}_{2} \mathrm{NNBrS}$ and $\mathrm{OHC}_{2} \mathrm{NNBrS}$ were calculated using group contribution method developed by Paduszyński et al. ${ }^{17}$ It has been shown that this model predict densities with high accuracy for a broad range of organic salts including dicationic and tricationic ionic liquids.

The magnitude and sign of excess molar volume of a binary mixture can be used as indicators of the strength of interactions between components in a mixture. Negative excess molar volumes were found in dilute aqueous solutions of $\mathrm{C}_{2} \mathrm{NNBrS}$ and $\mathrm{OHC}_{2} \mathrm{NNBrS}$. Excess molar volumes in dilute aqueous solutions of $\mathrm{C}_{2} \mathrm{NNBrS}$ and $\mathrm{OHC}_{2} \mathrm{NNBrS}$ (Fig. 4), and comparable values reported for hydrophilic protic ammonium based ionic liquids are listed in Table 3. The large negative values of $V_{m}{ }^{E}$ indicate that there is a significant association between the ZWS and a large number of water molecules, and that this association overcomes positive contribution to the $V_{m}{ }^{E}$ coming from the disruption of the water hydrogen-bond network. The association could be caused by formation of hydrogen bonds or improved molecular packing where water molecules fit efficiently into a network of ZWSs molecules in the higher mole fraction ZWS regime. The magnitude of the association is significant, particularly taking into account that this association is competing with the self-association of water molecules and ZWS self-association through ion-ion interactions (Fig. 2a). The excess molar volumes found for the ZWSs in dilute aqueous solution have significantly higher absolute values comparing to methylimidazolium halide ionic liquids ${ }^{18}$ and support the hypothesis of Ramjugernath and co-workers ${ }^{19}$ that the incorporation of polar and hydrophilic groups into organic cations would result in larger negative excess molar volumes. 
Table 4. Vapour pressure of water, $p$ (mbar) for the aqueous mixtures of $\mathrm{C}_{2} \mathrm{NNBrS}, \mathrm{OHC}_{2} \mathrm{NNBrS}$, and $\mathrm{COC}_{2} \mathrm{NNBrS}$ at given mass fraction ( $w_{z}$ ws) / mole fraction $\left(x_{\text {zws }}\right)$ measured at $T=25^{\circ} \mathrm{C}$.

\begin{tabular}{|c|c|c|c|}
\hline ZWS & $\mathrm{C}_{2} \mathrm{NNBrS}$ & $\mathrm{OHC}_{2} \mathrm{NNBrS}$ & $\mathrm{COC}_{2} \mathrm{NNBrS}$ \\
\hline $\boldsymbol{p} / \mathbf{m b a r}$ & 12 & 11 & 14 \\
\hline $\boldsymbol{w}_{\text {zws }}$ & 0.71 & 0.77 & 0.72 \\
\hline $\boldsymbol{X}_{\text {zws }}$ & 0.111 & 0.145 & 0.109 \\
\hline
\end{tabular}

To further explore the interactions of water with the ZWSs, vapour-liquid equilibria (VLE) were determined in order to assess water activity. Vapour pressure of water for three (ZWS + water) mixtures was determined at $25^{\circ} \mathrm{C}$ at $Z W S$ concentrations close to the salt solubility limit at room temperature and the results are shown in Table 4 . The values of water vapour pressure show highly non-ideal behaviour with pronounced negative deviations from Raoult's law. This is confirmation of the strong interactions between water and ZWS molecules, and opens up possibilities for the application of ZWS mixtures as a working pair for absorption cycle technology or as entrainers in extractive distillation.

Table 5. Minimum Inhibitory Concentration $(\mu \mathrm{m})$ of synthesised ZWSs

\begin{tabular}{|c|c|c|}
\hline ZWS & $\begin{array}{c}\text { MRSA } \\
\text { MIC }(\mu \mathrm{m})\end{array}$ & $\begin{array}{c}\text { P. aeruginosa PA01 } \\
\mathrm{MIC}(\mu \mathrm{m})\end{array}$ \\
\hline $\mathrm{C}_{2} \mathrm{NNBrS}$ & $>1024$ & $>1024$ \\
\hline $\mathrm{C}_{4} \mathrm{NNBrS}$ & $>1024$ & $>1024$ \\
\hline $\mathrm{C}_{6} \mathrm{NNBrS}$ & $>512$ & $>512$ \\
\hline
\end{tabular}

The preliminary toxicity study of ZWSs was carried out by evaluating of their antimicrobial activity. Minimum inhibitory concentrations (MICS) were calculated using standard broth microdilution assays according to NCCLS guideline ${ }^{20}$ and as described previously ${ }^{21}$. The test organisms were Staphylococcus aureus (methicillin resistant) MRSA ATCC 33593 (Gram positive) and Pseudomonas aeruginosa PA01 (Gram negative). The results for minimum inhibitory concentrations of three sulfonate based ZWSs (Table 5) show that the ZWSs were non-toxic to the tested bacteria. It is expected that longer alkyl chain ZWSs would display a moderate antimicrobial activity, similarly to the trend reported in previous studies on alkylated compounds such as 1-alkyl-3-methylimidazolium chlorides ${ }^{21}$.

\section{Conclusions}

ZWSs with a complex cation have been investigated as representative examples of this new ionic motif. The materials show strong hydrophilicity characterised by high solubility in water and a strong positive association with water molecules. These characteristics suggest applications in energy, industrial separations and biomedical fields as hydrophilic additives or as functional groups if attached on a polymer backbone. However, in order to further develop these potentially interesting new materials, it is necessary to expand the library with new structures (by systematic variation of the inter-charge chain, the chain length in the zwitterion moiety, type of the anion etc.) and evaluate their thermodynamic and transport properties, toxicity profile, and their specific atomistic interactions with water (hydration number, nature of hydrates) and solvent mixtures.

\section{Acknowledgements}

Authors thank Dr H. Q. Nimal Gunaratne for helpful discussions, and Pia McAleenan and Federico M. Ferrero Vallana for their help in the initial stage of the project.

\section{References}

1 Z. Q. Cao and S. Y. Jiang, Nano Today, 2012, 7, 404-413.

2 J. A. Callow and M. E. Callow, Nature Communications, 2011, 2.

3 Z. Zhang, S. F. Chen, Y. Chang and S. Y. Jiang, Journal of Physical Chemistry B, 2006, 110, 10799-10804.

4 X. F. Liu, L. L. Dong and Y. Fang, J. Surfactants Deterg., 2011, 14, 497-504.

5 X. P. Gao, F. Lu, B. Dong, T. Zhou, Y. Z. Liu and L. Q. Zheng, RSC Advances, 2015, 5, 63732-63737.

6 D. Bartczak and A. G. Kanaras, Langmuir, 2011, 27, 10119-10123.

7 T. Aoki, M. Harada and T. Okada, Langmuir, 2007, 23, 12473-12477.

8 T. Aoki, M. Harada and T. Okada, Langmuir, 2007, 23, 8820-8826.

9 Y. X. Wang, X. Huang, Y. J. Li, J. B. Wang and Y. L. Wang, Colloids and Surfaces a-Physicochemical and Engineering Aspects, 2009, 333, 108-114. 
10 A. Akcay, V. Balci and A. Uzun, Thermochimica Acta, 2014, 589, 131-136.

11 P. Wasserscheid and T. Welton, lonic Liquids in Synthesis, Wiley VCH, Weinheim, 2007.

12 K. Fucke, A. J. Edwards, M. R. Probert, S. E. Tallentire, J. A. K. Howard and J. W. Steed, Chemphyschem, 2013, 14, 675-679.

13 R. A. Horne, ed., Water and Aqeous Solution: Structure, Thermodynamics, and Trasport Properties, WileyInterscience, 1972.

14 G. Level, J. Jacquemin, J. Holbrey and M. Blesic, Manuscript in preparation, 2017.

15 M. Y. Hou, Y. J. Xu, Y. J. Han, B. Chen, W. X. Zhang, Q. H. Ye and J. Z. Sun, Journal of Molecular Liquids, 2013, 178, 149-155.

16 Y. J. Xu, Journal of Chemical Thermodynamics, 2013, 64, 126-133.

17 K. Paduszynski and U. Domanska, Ind. Eng. Chem. Res., 2012, 51, 591-604.

18 N. V. Sastry, N. M. Vaghela and P. M. Macwan, Journal of Molecular Liquids, 2013, 180, 12-18.

19 I. Bahadur, T. M. Letcher, S. Singh, G. G. Redhi, P. Venkatesu and D. Ramjugernath, Journal of Chemical Thermodynamics, 2015, 82, 34-46.

20 N. C. f. C. L. Standards, in National Committee for Clinical Laboratory Standards. , Wayne Pennsylvania, 1997, vol. M7-A4.

21 L. Carson, P. K. W. Chau, M. J. Earle, M. A. Gilea, B. F. Gilmore, S. P. Gorman, M. T. McCann and K. R. Seddon, Green Chemistry, 2009, 11, 492-497. 